\title{
Trends of caesarean section deliveries in Pakistan: secondary data analysis from Demographic and Health Surveys, 1990- 2018
}

Aaisha Amjad', Abeeha Imran', Nabeeha Shahram², Rubeena Zakar², Ahmed Usman', Muhammad Zakria Zakar ${ }^{3}$ and Florian Fischer ${ }^{4,5^{*}}$ (D)

\begin{abstract}
Background: Pakistan is among those countries where the number of caesarean section births has increased unusually in the past two decades. Therefore, the aim of the present study is to analyse the trend of caesarean section deliveries among child-bearing women (aged 15-49 years) in Pakistan and to identify maternal sociodemographic factors and pregnancy-related variables associated with the change in caesarean deliveries from 1990 to 2018.
\end{abstract}

Methods: Secondary data from Pakistan Demographic and Health Surveys (1990-2018) were analysed. The analysis of data was confined to child-bearing mothers. Sample sizes were 4029, 5721, 7461 and 8287 for the time periods of 1990-91, 2006-07, 2012-13 and 2017-18, respectively. Socio-demographic information of the mothers and pregnancy-related variables were taken as independent variables for the present study. The association between independent variables and caesarean deliveries was measured in terms of unadjusted odds ratios (OR) and adjusted OR (AOR).

Results: The percentages of the mothers who had at least one delivery during the 5 years prior to each survey who had caesarean deliveries increased continuously from 3.2\% in 1990-91 to 19.6\% in 2017-18. Results indicate that mothers over 24 years of age, located in Punjab, from the richest socio-economic class and living in urban areas were more likely to have delivered by caesarean section. Mothers with a first child in birth order and who had five and more children, as well as mothers who had more antenatal care visits and delivered babies in private hospitals showed a higher probability of caesarean section births.

* Correspondence: florian.fischer1@charite.de

${ }^{4}$ Institute of Public Health, Charité - Universitätsmedizin Berlin, Berlin, Germany

${ }^{5}$ Institute of Gerontological Health Services and Nursing Research, Ravensburg-Weingarten University of Applied Sciences, Weingarten, Germany Full list of author information is available at the end of the article

C The Author(s). 2020 Open Access This article is licensed under a Creative Commons Attribution 4.0 International License, which permits use, sharing, adaptation, distribution and reproduction in any medium or format, as long as you give appropriate credit to the original author(s) and the source, provide a link to the Creative Commons licence, and indicate if changes were made. The images or other third party material in this article are included in the article's Creative Commons licence, unless indicated otherwise in a credit line to the material. If material is not included in the article's Creative Commons licence and your intended use is not permitted by statutory regulation or exceeds the permitted use, you will need to obtain permission directly from the copyright holder. To view a copy of this licence, visit http://creativecommons.org/licenses/by/4.0/. The Creative Commons Public Domain Dedication waiver (http://creativecommons.org/publicdomain/zero/1.0/) applies to the data made available in this article, unless otherwise stated in a credit line to the data. 


\begin{abstract}
(Continued from previous page)
Conclusions: The findings of the present study confirm the gradual upsurge in the percentage of mothers delivering by caesarean section during the past two decades in Pakistan. Against this backdrop, some measures need to be taken by health departments to regulate the number of caesarean deliveries. Awareness among women about pregnancy complications and elaborated details by gynaecologists about the medically indicated reasons for caesarean delivery are a few important steps in Pakistan that can help in reducing caesarean deliveries which are not medically indicated.
\end{abstract}

Keywords: Caesarean delivery, Pregnancy complication, Antenatal care visit, Vaginal birth

\section{Background}

Convenient and immediate provision of health care facilities for pregnant women in all countries across the globe is highly important [1]. The instant availability of obstetric care for pregnant women also includes the provision of medical facilities for caesarean section deliveries [2]. Although caesarean sections are considered to be a safe surgical procedure [3], the progressive increase in caesarean births during the past few years has attracted the attention of public health experts globally [4]. In 2018, more than half of all deliveries were caesarean sections in Brazil, Egypt and Turkey. Data from the United States of America, Australia and Germany reveal that almost one in every three pregnant women has a caesarean section delivery [5]. Similarly, a rising trend of caesarean section deliveries has been documented in South Asian countries including Pakistan, where it increased from 3.2\% (1990) to $20 \%(2018)[5,6]$.

From 1985 to 2015, the international healthcare community considered the ideal rate for caesarean sections to be between 10 and $15 \%$. However, since the large increase in caesarean section rates, the World Health Organization no longer recommends a specific rate for countries to achieve related to their population level [7]. The findings of some ecological studies reveal that caesarean deliveries do not tend to reduce the mortality rate when it is above $10 \%$. Rather, the chances of mother and foetus mortality increases when the caesarean rate exceeds $15 \%$ [8-10]. Previous research highlights that the mortality rate becomes 2 to 4 times higher among the women who delivered through caesarean section compared to those who had a vaginal delivery $[8,9]$.

Although the new surgical techniques have played a significant role in reducing the postoperative implications, the persistent risks related to blood loss during operation, injury to baby, infection of the uterus scar and prolonged hospital stay cannot be completely overruled [10]. Furthermore, many studies reveal that women who deliver through caesarean section face adverse emotional and psychological problems, including postpartum depression and a saddening experience of childbirth after delivery [8-10]. In addition, research also shows that babies who are born through caesarean section may have a higher probability of experiencing weak immunity and respiratory issues in their later life [11].

Dystocia, previous delivery through caesarean section, size of the baby, cephalopelvic disproportion, prolonged labour and multiple gestations are the most frequent medical indications behind caesarean deliveries [12] However, the request of the mother for caesarean section can also be considered as a non-medical reason that has contributed to the upsurge of the caesarean rate [13, 14]. Literature also shows that mothers have several cultural or personal reasons behind requesting a caesarean delivery that may include their previous delivery experience, fear of vaginal birth and prolonged labour, and the cultural acceptability of caesarean sections [13]. Nevertheless, in Pakistan, a doctor's referral to perform caesarean section is considered to be a dominating reason over the pregnant woman's choice [4]. The increasing rate of caesarean deliveries in Pakistan is somewhat astonishing as most of the mothers residing in the country deliver babies at home. However, keeping in mind the misuse of caesarean sections, it can be speculated that gynaecologists may perform non-medically inflicted caesarean surgery to gain financial benefits, for time convenience and to gain surgical experience [4].

The discussion mentioned above highlights medical and non-medical factors contributing to an increase in the caesarean section rate in several countries around the globe. Due to the unusual upsurge in the caesarean rate during the last two decades, it is highly important to focus on actual data and time trends informing about the factors associated with caesarean deliveries. A previous study investigated these factors in Pakistan based on data from the Pakistan Demographic and Health Survey (PDHS) 2012-13 [3]. Another study was based on the previous three PDHS waves (1990-91, 2006-07 and 2012-13) but included only socio-demographic characteristics and not pregnancy-related variables [15]. The aim of this study is to fill the existing knowledge gap. The purpose of our study is 1) to analyse the trend of caesarean deliveries among child-bearing women in Pakistan and 2) identify various maternal sociodemographics and pregnancy-related variables associated 
with the change in caesarean deliveries over time from 1990 to 2018.

\section{Methods \\ Sample}

Secondary data from four waves (1990-2018) of PDHS were used for the present study. Demographic and Health Surveys (DHS) are conducted worldwide with the aim of providing consistent and authentic information about fertility and reproduction, maternal and childhood morbidity, the mother's nutritional level and domestic violence. The DHS datasets used the same stratified random sampling technique to select the participants for the research. The present study used the datasets of PDHS conducted in 1990-91, 2006-07, 2012-13 and 2017-18. Trained interviewers were hired to conduct surveys; they obtained the information required from the subjects through filling out the systematically designed questionnaire. The representative samples of evermarried women were 6611 (1990-91), 10,023 (2006-07), 13,558 (2012-13) and 15,068 (2017-18). The overall response rate was found to be above $90 \%$ for the data obtained during all four waves of PDHS. In the present study, the research data analysis was limited to mothers aged 15-49 years who had had at least one delivery in the 5 years prior to each survey. Therefore, the sample was 4029 in 1990-91, 5721 in 2006-07, 7461 in 201213 and 8287 in 2017-18.

\section{Variables}

We used caesarean section delivery as the outcome variable for the present study. Mothers were asked about the mode of their last delivery in the 5 years prior to each PDHS. The caesarean birth was labelled as "delivery by caesarean section" in the four sets of PDHSs, although there is no information about medical or nonmedical reasons for carrying out caesarean surgery.

Independent variables included socio-demographic characteristics of mothers and variables related to the pregnancy (e.g. pregnancy complications, antenatal care visits, termination of pregnancy, place of delivery).

Maternal socio-demographic variables analysed in the study are comparable to a previous study [4]. It included the mother's age at delivery of child (categorized to allow for large enough sub-groups: "<18", "18-20", "2124 " and "> 24 years"), level of education ("no education", "primary education", "middle education", "secondary education" and "higher education"), employment status (unskilled, skilled, technical/professional/managerial post, not employed), wealth index in quintiles ("poorest", "poorer", "middle", "richer" and "richest"), place of residence ("urban" and "rural") and regional areas ("Islamabad Capital Territory Punjab", "Balochistan", "Sindh", "Khyber Pukhtunkhwa", "Gilgit Baltistan",
"Azad Jammu and Kashmir" [AJK] and "FATA"). The earlier surveys of the PDHS do not provide data about Gilgit Baltistan as it was not recognised as a province before 2012. Moreover, Azad Jammu and Kashmir and FATA were only included in the most recent PDHS data conducted in 2017-18.

The birth order variable used in the study indicates the order of a child born to a mother during the previous 5 years and was recoded as " 1 ", " $2-3$ ", " $4-5$ " and " 6 and above". Pregnancy-related health concerns were measured by variables that included pregnancy complication ("yes" and "no") and the number of antenatal care visits during pregnancy, that was recoded as ("none", " $1-3$ " or " 4 and above"). The response of mothers was termed "yes" for those who were informed about any health problem, such as high blood pressure, diabetes or obesity, during their visit to a gynaecologist. Additionally, the place of delivery for a baby was recoded as "private" and "public" set-ups that included the private hospitals/clinics and government hospitals, respectively. We excluded all those deliveries that took place at home because delivering babies through caesarean section is not possible at home. The number of children born to a women during 5 years prior to each PDHS were recoded in the categories " $1-2$ ", " $3-4$ " and "5 and above". Mothers were asked questions regarding whether they had ever had a terminated pregnancy or not and the response categories were divided into "yes" and "no".

The characteristics of the newborn included the size and weight of the baby at birth. Information on birth weight was acquired from the baby's birth card. If the birth card was not available, the mother was asked about the weight of the baby at birth. The variable was dichotomised as "below average" ( $<2500 \mathrm{~g})$ and "normal" $(\geq 2500 \mathrm{~g})$. Fewer than $2 \%$ of mothers were able to relate the weight of the baby at birth in all PDHS. Therefore, they provided information about the size of the newborn at the time of delivery. The variable presenting the size of the baby was also recoded as "normal" and "below average". Recoded variables related to the size and weight of the baby were combined together to obtain a new variable related to the size of the baby at birth that was considered as "normal" and "below average".

\section{Data analysis}

Data were analysed by using SPSS version 21 . We used the sample weights provided by the DHS to deal with the complex sampling design used in the surveys. The weighting enables us to generalise the findings of the present study to all women of the retrospective age group living in Pakistan. Descriptive statistics were shown in the form of frequencies and percentages. A simple binary and multivariate logistic regression were 
used to assess the association between the independent variables and the dependent variable. Multicollinearity was tested by using the variance inflation factor. Its results indicated no multicollinearity, therefore, all variables could be retained in the model. The association between a dependent variable (caesarean births) and independent variables was indicated by the values of OR and AOR with $95 \%$ confidence intervals (CI). The inclusion of independent variables in the multivariate logistic regression analysis was based on the significance level of $p<0.05$. All the independent variables $(p<0.05$ in binary logistic regression) were entered simultaneously to calculate the AOR through multivariate logistic regression analysis.

\section{Results}

\section{Maternal socio-demographic characteristics}

Of the mothers who had a delivery in the 5 years preceding the survey, $40.5 \%$ were less than 18 years old in 1990-91. This percentage reduced slightly in 2006-07 (39.6\%) and 2012-13 (27.2\%). The trend continued in 2017-18 and the percentage was further reduced to $26.8 \%$. Regarding education, $76.7 \%$ women were uneducated in 1990-91. However, this trend reduced in 2006-07 (66.6\%), 2012-13 (55.8\%) and 2017-18 (50.4\%). The majority of mothers were non-working in 1990-91 (85.0\%), which decreased by a small proportion in 2006-07 (71.5\%) and 2012-13 (72.23\%). The percentage of non-working mothers was highest in 2017-18 (86.7\%). Additionally, the proportion of women living in rural areas and residing in the Punjab region expanded over the years (Table 1). The percentages of mothers who had caesarean section was almost $3.2 \%$ in $1990-91,7.8 \%$ in $2006-07,13.6 \%$ in $2012-13$ and $19.6 \%$ in $2017-18$. The distribution of caesarean sections among socio-demographic and pregnancy-related characteristics is shown in Table 2.

\section{Simple binary logistic regression}

The analysis of data in simple binary logistic regression models (Table 3) revealed that the age of the mother was significantly associated with caesarean section deliveries in all datasets of PDHSs, with higher rates among women with higher ages. Furthermore, the children's birth order was strongly associated with the caesarean section deliveries. This is also visible for the mother's education, as higher education is associated with a higher likelihood of caesarean section deliveries. This association overall applies to the mother's education and employment. The likelihood of caesarean deliveries among women living in urban compared to rural areas was inconsistent between the four PDHS waves.

Mothers having had pregnancy complications previously were significantly more likely to deliver via caesarean section in $2006-07$ (OR $=2.20,95 \%$ CI: $1.78-2.72)$ and 2012-13 (OR $=1.68,95 \% \mathrm{CI}: 1.45-1.94)$, whereas data were not available for 1990-91 and 2017-18. Similarly, the trend of caesarean deliveries among mothers who received antenatal care four times and more remained significant in all four datasets. Additionally, a significant relationship was found among mothers delivering babies in private sector hospitals and caesarean deliveries in 2012-13 (OR = 1.33, 95\% CI: $1.14-1.54)$ and 2017-18 (OR $=1.85$, 95\% CI: 1.64-2.09). Moreover, no significant association was found between the size of the baby at birth and caesarean deliveries in three of the datasets of PDHSs (1990-91, 2012-13 and 2017-18). However, in 2006-07, mothers having a normal size baby at birth $(\mathrm{OR}=0.81,95 \% \mathrm{CI}$ : $0.63-0.99)$ had higher chances of caesarean deliveries. Pregnancy termination was insignificant in all three datasets in which data was available. Furthermore, data showed that mothers having 1-2 children were significantly related with caesarean deliveries in all four datasets.

\section{Multivariable logistic regression}

Using multivariable logistic regression analysis (Table 4), the data showed that mothers who had antenatal care visits more than four times had a higher likelihood of delivering babies through caesarean section in all four datasets. Pregnancy complications were also significantly associated in the two waves where the item has been assessed. Mothers aged more than 24 years were found to have a greater chance of giving birth through caesarean section in 2012-13 (AOR $=1.73$, 95\% CI: $1.37-2.24)$ and $2017-$ $18(\mathrm{OR}=1.79,95 \% \mathrm{CI}: 1.43-2.22)$. Mothers with a first child remained significant only in the PDHS 2017-18 (AOR $=0.13,95 \%$ CI: 0.07-0.22). Moreover, mothers with higher education were found to be associated with caesarean section deliveries in 1990-91 $(\mathrm{AOR}=8.60, \quad 95 \% \quad \mathrm{CI}: \quad 2.00-36.92)$ and $2017-18$ $(\mathrm{AOR}=1.35,95 \% \mathrm{CI}: 1.07-1.69)$.

The mother's occupation, pregnancy termination and size of the baby remained insignificant in all PDHS surveys. Mothers who belonged to the richest class showed a persistently strong association with caesarean deliveries in $2006-07(\mathrm{AOR}=3.25,95 \% \mathrm{CI}: 1.57-6.70), 2012-13$ $(\mathrm{AOR}=1.66,95 \% \mathrm{CI}: 1.08-2.54)$ and $2017-18(\mathrm{AOR}=$ 2.20, 95\% CI: 1.59-3.05). Considering the place of delivery, it was found that mothers who delivered babies in private hospitals were more likely to deliver children by caesarean compared to public hospitals $(\mathrm{AOR}=1.45$, 95\% CI: 1.26-1.68) in PDHS 2017-18. Moreover, the results showed that mothers who had 1-2 children had higher chances of caesarean deliveries compared to 5 children and above only in 2017-18 (AOR $=0.08,95 \%$ CI: 1.44-1.67). 
Table 1 Socio-demographic characteristics of child-bearing women aged 15-49years (weighted percentages)

\begin{tabular}{|c|c|c|c|c|c|c|c|c|}
\hline & \multicolumn{2}{|c|}{$\begin{array}{l}\text { PDHS 1990-91 } \\
(n=4029)\end{array}$} & \multicolumn{2}{|c|}{$\begin{array}{l}\text { PDHS 2006-07 } \\
(n=5721) \\
\end{array}$} & \multicolumn{2}{|c|}{$\begin{array}{l}\text { PDHS 2012-13 } \\
(n=7461)\end{array}$} & \multicolumn{2}{|c|}{$\begin{array}{l}\text { PDHS 2017-18 } \\
(n=8287)\end{array}$} \\
\hline & $\mathrm{n}$ & $\%$ & $n$ & $\%$ & $n$ & $\%$ & $\mathrm{n}$ & $\%$ \\
\hline \multicolumn{9}{|c|}{ Mother's age at birth (in years) } \\
\hline Less than 18 & 1631 & 40.5 & 1902 & 39.6 & 2025 & 27.2 & 2217 & 26.8 \\
\hline $18-20$ & 807 & 20.0 & 1224 & 25.5 & 1661 & 22.3 & 1801 & 21.7 \\
\hline $21-24$ & 1056 & 26.2 & 556 & 11.6 & 2394 & 32.1 & 2563 & 30.9 \\
\hline More than 24 & 535 & 13.3 & 1120 & 23.3 & 1367 & 18.4 & 1706 & 20.6 \\
\hline \multicolumn{9}{|l|}{ Mother's education } \\
\hline No education & 3089 & 76.7 & 3811 & 66.6 & 4155 & 55.8 & 4178 & 50.4 \\
\hline Primary & 372 & 9.2 & 789 & 13.8 & 1230 & 16.5 & 1101 & 13.3 \\
\hline Middle & - & - & - & - & 587 & 7.9 & - & - \\
\hline Secondary & 503 & 12.5 & 763 & 13.3 & 792 & 10.6 & 1747 & 21.1 \\
\hline higher & 65 & 1.6 & 361 & 6.3 & 682 & 9.2 & 1261 & 15.2 \\
\hline \multicolumn{9}{|l|}{ Mother's occupation } \\
\hline Not working & 3422 & 85.0 & 4092 & 71.5 & 5378 & 72.2 & 7183 & 86.7 \\
\hline Unskilled & 64 & 1.6 & 158 & 2.8 & 938 & 12.6 & 46 & 6 \\
\hline Skilled & 495 & 12.3 & 1364 & 23.8 & 990 & 13.3 & 806 & 9.7 \\
\hline Prof/tech/managerial & 45 & 1.1 & 106 & 1.9 & 140 & 1.9 & 249 & 3.0 \\
\hline \multicolumn{9}{|l|}{ Type of residence } \\
\hline Urban & 2011 & 49.9 & 1998 & 34.9 & 2244 & 30.1 & 3738 & 45.1 \\
\hline Rural & 2018 & 50.1 & 3726 & 65.1 & 5202 & 69.9 & 4549 & 54.9 \\
\hline \multicolumn{9}{|l|}{ Region } \\
\hline Punjab & 1355 & 33.6 & 2305 & 40.3 & 4180 & 56.1 & 1740 & 21.0 \\
\hline Sindh & 1066 & 26.5 & 1626 & 28.4 & 1714 & 23.0 & 1474 & 17.8 \\
\hline KPK & 1043 & 25.9 & 1113 & 19.4 & 1117 & 15.0 & 1386 & 16.7 \\
\hline Balochistan & 565 & 14.0 & 680 & 11.9 & 348 & 4.7 & 1005 & 12.1 \\
\hline Gilgit Baltistan & - & - & - & - & 56 & 0.7 & 614 & 7.4 \\
\hline Islamabad (CT) & - & - & - & - & 31 & 0.4 & 546 & 6.6 \\
\hline AJK & - & - & - & - & - & - & 870 & 10.5 \\
\hline FATA & - & - & - & - & - & - & 652 & 7.9 \\
\hline \multicolumn{9}{|l|}{ Wealth index } \\
\hline Poorest & - & - & 1289 & 22.5 & 1698 & 22.8 & 1827 & 22.0 \\
\hline Poorer & - & - & 1235 & 21.6 & 1544 & 20.7 & 1863 & 22.5 \\
\hline Middle & - & - & 1118 & 19.5 & 1464 & 19.7 & 1622 & 19.6 \\
\hline Richer & - & - & 1064 & 18.6 & 1469 & 19.4 & 1486 & 17.9 \\
\hline Richest & - & - & 1018 & 17.8 & 1272 & 17.1 & 1489 & 18.0 \\
\hline
\end{tabular}

\section{Discussion}

The results reveal a drastic increase in caesarean deliveries among Pakistani women from $3.2 \%$ in 1990 to $19.6 \%$ in 2018. Further studies conducted in Pakistan reveal that foetal distress, prolonged labour pain, wound sepsis, previous caesarean history and rupture of placenta are the most common medical factors of caesarean section deliveries in the hospitals in Pakistan [16, 17]. The high cost of caesarean delivery is sometimes considered as a higher social status symbol. Such perception might be adding to the increasing trend of caesarean deliveries. Nevertheless, in Pakistan and other developing countries, where patients are rarely given an option to choose the mode of delivery, the doctor's referrals for caesarean delivery can be a possible reason behind the increasing trend of caesarean deliveries [18].

The age of mothers at the time of delivery emerged as one of the contributing factors, as there is a strong 
Table 2 Socio-demographics and pregnancy-related variables associated with caesarean deliveries (weighted percentages)

\begin{tabular}{|c|c|c|c|c|}
\hline & $\begin{array}{l}\text { PDHS 1990-91 } \\
(n=4029)\end{array}$ & $\begin{array}{l}\text { PDHS 2006-07 } \\
(n=5721)\end{array}$ & $\begin{array}{l}\text { PDHS 2012-13 } \\
(n=7461)\end{array}$ & $\begin{array}{l}\text { PDHS 2017-18 } \\
(n=8287)\end{array}$ \\
\hline Rate of caesarean deliveries & $3.2 \%$ & $7.8 \%$ & $13.6 \%$ & $19.6 \%$ \\
\hline \multicolumn{5}{|l|}{ Socio-demographics } \\
\hline \multicolumn{5}{|l|}{ Mother's age at birth (in years) } \\
\hline Less than 18 & $2.4 \%$ & $3.8 \%$ & $7.2 \%$ & $9.3 \%$ \\
\hline $18-20$ & $2.5 \%$ & $6.6 \%$ & $11.9 \%$ & $15.3 \%$ \\
\hline $21-24$ & $4.5 \%$ & $7.6 \%$ & $18.9 \%$ & $21.8 \%$ \\
\hline More than 24 & $4.1 \%$ & $9.3 \%$ & $27.6 \%$ & $34.3 \%$ \\
\hline \multicolumn{5}{|l|}{ Children's birth order } \\
\hline 1 & $6.3 \%$ & $14.3 \%$ & $25.5 \%$ & $27.4 \%$ \\
\hline $2-3$ & $3.6 \%$ & $10.5 \%$ & $19.6 \%$ & $24.2 \%$ \\
\hline $4-5$ & $3.2 \%$ & $6.1 \%$ & $10.5 \%$ & $17.4 \%$ \\
\hline 6 and above & $1.2 \%$ & $2.9 \%$ & $6.1 \%$ & $7.0 \%$ \\
\hline \multicolumn{5}{|l|}{ Mother's education } \\
\hline No education & $1.4 \%$ & $3.9 \%$ & $7.5 \%$ & $9.1 \%$ \\
\hline Primary & $5.1 \%$ & $10.4 \%$ & $17.1 \%$ & $18.3 \%$ \\
\hline Middle & - & - & $21.3 \%$ & - \\
\hline Secondary & $10.8 \%$ & $16.4 \%$ & $31.5 \%$ & $28.8 \%$ \\
\hline Higher & $16.9 \%$ & $25.3 \%$ & $40.2 \%$ & $42.9 \%$ \\
\hline \multicolumn{5}{|l|}{ Mother's occupation } \\
\hline Not working & $3.3 \%$ & $8.8 \%$ & $18.1 \%$ & $19.4 \%$ \\
\hline Unskilled & $1.6 \%$ & $5.1 \%$ & $11.4 \%$ & $15.2 \%$ \\
\hline Skilled & $2.3 \%$ & $4.0 \%$ & $5.3 \%$ & $16.0 \%$ \\
\hline Professional/Technical/ Managerial & $11.4 \%$ & $21.9 \%$ & $30.0 \%$ & $39.5 \%$ \\
\hline \multicolumn{5}{|l|}{ Wealth index } \\
\hline Poorest & - & $1.9 \%$ & $7.5 \%$ & $6.1 \%$ \\
\hline Poorer & - & $2.4 \%$ & $17.1 \%$ & $9.8 \%$ \\
\hline Middle & - & $5.6 \%$ & $21.3 \%$ & $18.6 \%$ \\
\hline Richer & - & $11.3 \%$ & $31.5 \%$ & $29.0 \%$ \\
\hline Richest & - & $20.6 \%$ & $40.2 \%$ & $40.2 \%$ \\
\hline \multicolumn{5}{|l|}{ Type of residence } \\
\hline Rural & $1.2 \%$ & $5.1 \%$ & $11.5 \%$ & $14.4 \%$ \\
\hline Urban & $5.2 \%$ & $12.8 \%$ & $25.6 \%$ & $26.0 \%$ \\
\hline \multicolumn{5}{|l|}{ Region } \\
\hline Baluchistan & $0.7 \%$ & $2.2 \%$ & $1.7 \%$ & $5.7 \%$ \\
\hline Islamabad Capital Territory & - & - & $28.1 \%$ & $31.7 \%$ \\
\hline Punjab & $4.8 \%$ & $11.4 \%$ & $19.1 \%$ & $31.0 \%$ \\
\hline Sindh & $3.5 \%$ & $7.4 \%$ & $17.4 \%$ & $27.0 \%$ \\
\hline Khyber Pakhtunkhwa & $2.1 \%$ & $4.4 \%$ & $5.2 \%$ & $10.0 \%$ \\
\hline Gilgit Baltistan & - & - & $3.6 \%$ & $12.1 \%$ \\
\hline AJK & - & - & - & $25.4 \%$ \\
\hline FATA & - & - & - & $3.8 \%$ \\
\hline
\end{tabular}


Table 2 Socio-demographics and pregnancy-related variables associated with caesarean deliveries (weighted percentages) (Continued)

\begin{tabular}{|c|c|c|c|c|}
\hline & $\begin{array}{l}\text { PDHS 1990-91 } \\
(n=4029)\end{array}$ & $\begin{array}{l}\text { PDHS 2006-07 } \\
(n=5721)\end{array}$ & $\begin{array}{l}\text { PDHS 2012-13 } \\
(n=7461)\end{array}$ & $\begin{array}{l}\text { PDHS 2017-18 } \\
(n=8287)\end{array}$ \\
\hline \multicolumn{5}{|c|}{ Pregnancy-related variables } \\
\hline \multicolumn{5}{|c|}{ Pregnancy complication } \\
\hline No & - & $9.0 \%$ & $14.9 \%$ & - \\
\hline Yes & - & $17.9 \%$ & $25.2 \%$ & - \\
\hline \multicolumn{5}{|c|}{ Number of antenatal care visits } \\
\hline None & $1.0 \%$ & $4.0 \%$ & $22.1 \%$ & $1.9 \%$ \\
\hline $1-3$ & $4.6 \%$ & $11.3 \%$ & $10.7 \%$ & $10.9 \%$ \\
\hline 4 and above & $8.5 \%$ & $19.3 \%$ & $30.1 \%$ & $31.3 \%$ \\
\hline \multicolumn{5}{|c|}{ Place of delivery } \\
\hline Public & $15.9 \%$ & $21.1 \%$ & $28.9 \%$ & $22.5 \%$ \\
\hline Private & $14.8 \%$ & $21.3 \%$ & $31.2 \%$ & $34.9 \%$ \\
\hline \multicolumn{5}{|c|}{ Size of the baby at birth } \\
\hline Below average & $13.9 \%$ & $6.8 \%$ & $37.9 \%$ & $20.9 \%$ \\
\hline Normal & $13.0 \%$ & $8.3 \%$ & $32.1 \%$ & $19.4 \%$ \\
\hline \multicolumn{5}{|c|}{ Number of children } \\
\hline $1-2$ & $4.9 \%$ & $12.7 \%$ & $20.4 \%$ & $26.3 \%$ \\
\hline $3-4$ & $3.6 \%$ & $8.0 \%$ & $13.4 \%$ & $20.5 \%$ \\
\hline 5 and above & $1.7 \%$ & $2.9 \%$ & $5.8 \%$ & $8.7 \%$ \\
\hline \multicolumn{5}{|c|}{ Pregnancy ever terminated } \\
\hline No & - & $9.9 \%$ & $13.2 \%$ & $20.9 \%$ \\
\hline Yes & - & $8.5 \%$ & $14.5 \%$ & $21.9 \%$ \\
\hline
\end{tabular}

relationship between the age of the mother and the mode of delivery (caesarean or vaginal). Many studies revealed that older mothers have a higher likelihood of caesarean deliveries $[19,20]$. No research has been conducted to show the factors for the increased number of caesarean deliveries in the older mothers. However, it can be assumed that older mothers have more chances of having pregnancy complications that may result in caesarean deliveries [21]. Even in the absence of pregnancy-related complications, older mothers are more inclined to give birth through caesarean section [20]. Women in Pakistan have become more career conscious in terms of acquiring education and choosing a suitable job to earn their livelihood during the last few years [4]. The extensive process of becoming financially independent results into delayed marriages of women and, thus, increases their age for conception [22]. The increased age of a woman at the time of conception tends to have complications in the later period of the pregnancy that can possibly lead to a caesarean delivery [23]. Thus, it could be a possible reason for increased caesarean compared to vaginal deliveries.

Previous studies have revealed that women who reported having medical problems, such as chronic hypertension, chronic infections, heart problems or respiratory diseases, have a higher tendency of caesarean section births [24]. In correspondence to previous studies [24, 25], our results also showed that mothers who reported having complications, such as urinary tract infections, obesity or preeclampsia at any stage of pregnancy, had a higher tendency of caesarean delivery. On the other hand, PDHSs 1990-91 and 2017-18 did not include the questions related to pregnancy complications.

As per findings of previous clinical studies [26, 27], frequent visits to antenatal care facilities, pregnancy complications and the mode of delivering a baby are strongly associated. Considering the importance of antenatal care in the reduction of complications, a new World Health Organization guideline emphasises that every pregnant woman should have at least eight antenatal care visits during each pregnancy [4]. Findings of previous studies also revealed that antenatal care is considered an important component of women's health during the course of pregnancy that can play a pivotal role in reducing the likelihood of caesarean deliveries [2628]. By contrast, our study reveals a persistent upsurge of caesarean deliveries for mothers with more than four 
Table 3 Simple binary logistic regression of socio-demographics and pregnancy-related variables associated with caesarean deliveries

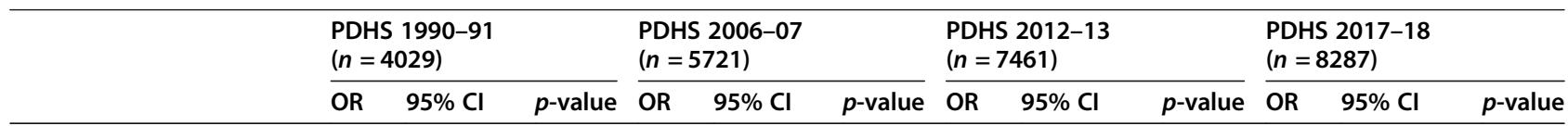

\section{Socio-demographics}

\section{Mother's age at birth} (in years)

Less than 18

18-20

21-24

More than 24

Children birth order

$\begin{array}{llllllllllllll}1 & 5.38 & 2.94-9.83 & <0.001 & 0.46 & 0.30-0.71 & <0.001 & 5.06 & 3.95-6.48 & <0.001 & 5.00 & 3.97-6.29 & <0.001 \\ 2-3 & 3.04 & 1.68-5.51 & <0.001 & 2.58 & 1.83-3.66 & <0.001 & 3.43 & 2.71-4.33 & <0.001 & 4.24 & 3.41-5.27 & <0.001 \\ 4-5 & 2.68 & 1.44-4.98 & <0.001 & 1.82 & 1.31-2.54 & <0.001 & 1.56 & 1.19-2.04 & <0.001 & 2.80 & 2.18-3.60 & <0.001 \\ \text { More than 6 } & 1 & & & 1 & & & 1 & & & 1 & & \end{array}$

\section{Mother's education}

No education

Primary

Middle

Secondary

Higher

\section{Mother's occupation}

Not working

Unskilled

Skilled

Professional/Technical/ Managerial

\section{Wealth index}

Poorest

Poorer

Middle

Richer

Richest

\section{Type of residence}

Rural

Urban

\section{Region}

Baluchistan

Islamabad Capital Territory

Punjab

$3.78 \quad 2.18-6.56<0.001$

$-$

$8.46 \quad 5.60-12.78<0.001$

$14.19 \quad 6.94-29.01<0.001$

\section{1}

$2.85 \quad 2.15-3.77<0.001$

266

$2.66 \quad 2.15-3.29$

$<0.001$

1

$1.07 \quad 0.62-1.84 \quad 0.822 \quad 1.80 \quad 1.30-2.50 \quad<0.001 \quad 1.66 \quad 1.31-2.10$

$\begin{array}{llll}1.96 & 1.26-3.02 & <0.001 & 2.08\end{array}$

$1.40-3.08$

$0.001 \quad 2.74 \quad 2.23-3.37$

$<0.001$

$1.46-2.14$

$<0.001$

$1.78 \quad 1.05-3.04 \quad<0.001 \quad 2.60$

$-\quad-\quad-\quad-10$

3.52

$4.81 \quad 3.74-6.19<0.001$

5.22

$2.74-4.52$

8.31

$6.23-11.09<0.001$

7.86

$4.26-6.40$

$6.51-9.49$

1

$0.47 \quad 0.07-3.43 \quad 0.457$

$0.69 \quad 0.37-1.29 \quad 0.241$

$3.81 \quad 1.47-9.84<0.001$

0.44

$0.27-1.14<0.001$

$$
\begin{array}{lllll}
2.92 & 1.81-4.69 & <0.001 & 2.15 & 1.53-3.02
\end{array}
$$

$<0.001$

$<0.00$

$<0.00$
$<0.001$

$<0.001$

0.001

0.001

0.001 
Table 3 Simple binary logistic regression of socio-demographics and pregnancy-related variables associated with caesarean deliveries (Continued)

\begin{tabular}{|c|c|c|c|c|c|c|c|c|c|c|c|c|}
\hline & \multicolumn{3}{|c|}{$\begin{array}{l}\text { PDHS 1990-91 } \\
(n=4029)\end{array}$} & \multicolumn{3}{|c|}{$\begin{array}{l}\text { PDHS 2006-07 } \\
(n=5721)\end{array}$} & \multicolumn{3}{|c|}{$\begin{array}{l}\text { PDHS 2012-13 } \\
(n=7461)\end{array}$} & \multicolumn{3}{|c|}{$\begin{array}{l}\text { PDHS 2017-18 } \\
(n=8287)\end{array}$} \\
\hline & $\overline{\mathrm{OR}}$ & $95 \% \mathrm{Cl}$ & $p$-value & OR & $95 \% \mathrm{Cl}$ & $p$-value & OR & $95 \% \mathrm{Cl}$ & $p$-value & OR & $95 \% \mathrm{Cl}$ & $p$-value \\
\hline \multicolumn{13}{|c|}{ Pregnancy-related variables } \\
\hline \multicolumn{13}{|c|}{ Pregnancy complication } \\
\hline No & - & - & - & 1 & & & 1 & & & - & - & - \\
\hline Yes & - & - & - & 2.20 & $1.78-2.72$ & $<0.001$ & 1.68 & $1.45-1.94$ & $<0.001$ & - & - & - \\
\hline \multicolumn{13}{|c|}{$\begin{array}{l}\text { Number of antenatal care } \\
\text { visits }\end{array}$} \\
\hline None & 1 & & & 1 & & & 1 & & & 1 & & \\
\hline $1-3$ & 5.08 & $2.97-9.68$ & $<0.001$ & 3.05 & $2.17-4.28$ & $<0.001$ & 6.21 & $4.15-9.31$ & $<0.001$ & 6.31 & $4.15-9.61$ & $<0.001$ \\
\hline 4 and above & 9.70 & $6.01-15.72$ & $<0.001$ & 5.76 & $4.63-7.15$ & $<0.001$ & 25.40 & $17.22-37.47$ & $<0.001$ & 23.36 & $15.52-35.18$ & $<0.001$ \\
\hline \multicolumn{13}{|c|}{ Place of delivery } \\
\hline Public & 1 & & & 1 & & & 1 & & & 1 & & \\
\hline Private & 0.92 & $0.61-1.39$ & 0.696 & 1.01 & $0.81-1.26$ & 0.938 & 1.33 & $1.14-1.54$ & $<0.001$ & 1.85 & $1.64-2.09$ & $<0.001$ \\
\hline \multicolumn{13}{|c|}{ Size of the baby at birth } \\
\hline Below average & 1 & & & 1 & & & 1 & & & 1 & & \\
\hline Normal & 1.08 & $0.38-3.07$ & 0.888 & 0.81 & $0.63-0.99$ & $<0.001$ & 1.29 & $0.95-1.75$ & 0.103 & 1.10 & 1.26 & 0.180 \\
\hline \multicolumn{13}{|c|}{ Number of children } \\
\hline $1-2$ & 0.34 & $0.21-0.53$ & $<0.001$ & 0.21 & $0.15-0.27$ & $<0.001$ & 0.24 & $0.20-0.29$ & $<0.001$ & 0.27 & $0.23-0.32$ & $<0.001$ \\
\hline $3-4$ & 0.72 & $0.48-1.09$ & 0.116 & 0.60 & $0.48-0.75$ & $<0.001$ & 0.60 & $0.52-0.70$ & $<0.001$ & 0.72 & $0.64-0.82$ & $<0.001$ \\
\hline 5 and above & 1 & & & 1 & & & 1 & & & 1 & & \\
\hline \multicolumn{13}{|c|}{$\begin{array}{l}\text { Pregnancy ever } \\
\text { terminated }\end{array}$} \\
\hline No & - & - & - & 1 & & & 1 & & & 1 & & \\
\hline Yes & - & - & - & 1.12 & $0.90-1.40$ & 0.310 & 1.11 & $0.97-1.28$ & 0.136 & 1.06 & $0.80-1.41$ & 0.675 \\
\hline
\end{tabular}

antenatal care visits more. Although there is no clear reason behind this, it can be assumed that women with pregnancy complications, such as obesity, hypertension and diabetes, were asked by the gynaecologists to have frequent antenatal care visits in order to handle any undesirable obstetric risk. While considering the regional demographics, the women from Punjab's region persistently show a higher tendency towards caesarean deliveries. Feasible access and the availability of health care facilities at private and public hospitals can be traced as one of the factors behind increased caesarean deliveries in the province $[4,28]$.

Studies conducted in Bangladesh [29] and India [30] indicated that mothers belonging to a higher socioeconomic class had a higher tendency to opt for caesarean section. In such cases, caesarean delivery seems to be a desire of woman who can afford it rather than the doctor's referral for a safe childbirth process [31]. Moreover, research conducted in different countries also highlights that caesarean deliveries are more prevalent in women belonging to a higher socio-economic class as they have a misconception that caesarean delivery is the highest quality of obstetric care [6,32]. Similarly, our study shows that a better socio-economic status is one of the significant factors behind increased caesarean section rates. It is obvious that a higher socio-economic status provides sufficient finances to bear the higher expenditure of caesarean surgery. Thus, caesarean section is more prevalent in women belonging to a higher socio-economic class [33]. On the other hand, women belonging to a lower socioeconomic status might not be able to afford the expenses of caesarean delivery or do not have access to the obstetric care facilities required for caesarean delivery. Therefore, the rate of caesarean deliveries is found to be lower in women having a poor socio-economic status [31].

Although it has been recognised that caesarean deliveries may support a reduction in the mother and child mortality rate, malpractices linked with caesarean surgery cannot be neglected [34]. A study conducted in India shows that the number of caesarean deliveries in private hospitals are three times higher than in public hospitals [33]. Similarly, the present study reveals that the rate of caesarean deliveries is increasing in private 
Table 4 Multivariable logistic regression of socio-demographics and pregnancy-related variables associated with caesarean deliveries

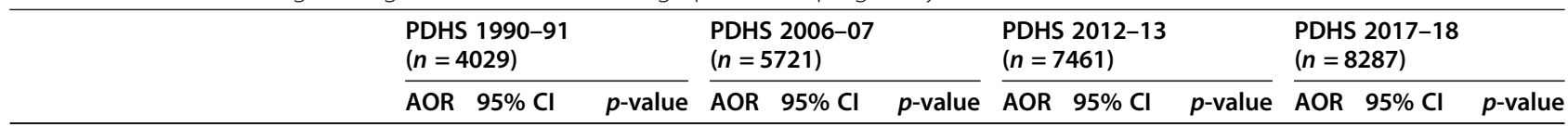

\section{Socio-demographics}

\section{Mother's age at birth (in years)}

Less than 18

18-20

21-24

More than 24

\section{Children's birth order}

1

2-3

4-5

6 and above

\section{Mother's education}

No education

Primary

Middle

Secondary

Higher

$\begin{array}{ll}- & - \\ - & - \\ - & - \\ - & -\end{array}$

$-$

Mother's occupation

Not working

Unskilled

Skilled

$\begin{array}{llllllllllll}5.99 & 0.89-40.18 & 0.650 & 0.90 & 0.46-1.77 & 0.758 & 1.17 & 0.67-2.04 & 0.590 & 0.13 & 0.07-0.22 & <0.001 \\ 7.30 & 1.48-36.02 & 0.151 & 2.04 & 1.09-3.80 & <0.001 & 0.90 & 0.54-1.50 & 0.676 & 0.13 & 0.07-0.23 & <0.001 \\ 8.10 & 1.54-37.04 & 0.104 & 1.63 & 1.00-2.66 & <0.001 & 0.70 & 0.46-1.06 & 0.090 & 0.11 & 0.06-0.20 & <0.001 \\ 1 & & & 1 & & & 1 & & & 1 & & \end{array}$

Professional/Technical/Managerial

\begin{tabular}{lllllllllllll}
1 & & & 1 & & \multicolumn{1}{c}{1} & & & 1 & \\
1.91 & $0.59-6.15$ & 0.279 & 1.28 & $0.86-1.91$ & 0.219 & 1.04 & $0.80-1.35$ & 0.788 & 0.86 & $0.68-1.08$ & 0.182 \\
- & - & - & - & - & - & - & - & - & - & - & - \\
4.93 & $1.97-12.34$ & $<0.001$ & 1.21 & $0.81-1.80$ & 0.353 & 1.04 & $0.81-1.34$ & 0.740 & 1.09 & $0.89-1.34$ & 0.387 \\
8.60 & $2.00-36.92$ & $<0.001$ & 0.99 & $0.56-1.73$ & 0.985 & 1.12 & $0.84-1.48$ & 0.440 & 1.35 & $1.07-1.69$ & $<0.001$
\end{tabular}

\section{Wealth index}

Poorest

Poorer

Middle

Richer

Richest

\section{Type of residence}

Rural
Urban
Region
Baluchistan
Islamabad Capital Territory
Punjab
Sindh
Khyber Pakhtunkhwa
Gilgit Baltistan
AJK
FATA

$2.37 \quad 0.77-7.31 \quad 0.135$
$1.26 \quad 0.85-1.85 \quad 0.250$

$\begin{array}{lll}1.31 & 0.81-2.22 & 0.267\end{array}$

$\begin{array}{lll}1.30 & 0.89-1.92 & 0.179\end{array}$

$1.10 \quad 0.84-1.44 \quad 0.511$

$1.12 \quad 0.90-1.41 \quad 0.315$

$1.40 \quad 1.09-1.78<0.001 \quad 1.30 \quad 1.06-1.60<0.001$

$1.73 \quad 1.37-2.24<0.001$

$1.79 \quad 1.43-2.22<0.001$

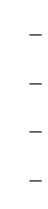

\section{1}

$\begin{array}{lll}- & - \\ - & - \\ - & - \\ - & -\end{array}$

$0.72 \quad 0.44-1.15 \quad 0.169$

$\begin{array}{lll}1.50 & 0.63-3.57 & 0.360\end{array}$

$\begin{array}{llll}0.89 & 0.58-1.36 & 0.583\end{array}$

$\begin{array}{lll}1.05 & 0.44-2.51 & 0.912\end{array}$

1.06

1.04

$0.80-1.42 \quad 0.671$

$0.70-1.54 \quad 0.858$

1

$0.68 \quad 0.13-3.54 \quad 0.642$

$\begin{array}{lll}1.09 & 0.74-1.62 & 0.659\end{array}$

$\begin{array}{llll}0.78 & 0.43-1.41 & 0.407\end{array}$

\begin{tabular}{|c|c|c|c|c|c|c|c|c|c|c|c|}
\hline 1 & & & 1 & & & 1 & & & 1 & & \\
\hline - & - & - & - & - & - & 0.38 & $0.23-0.64$ & $<0.001$ & 0.39 & $0.28-0.52$ & $<0.001$ \\
\hline 0.30 & $0.07-1.38$ & 0.122 & 0.69 & $0.49-0.96$ & $<0.001$ & 1.95 & $1.48-2.57$ & $<0.001$ & 0.88 & $0.73-1.07$ & 0.209 \\
\hline 0.37 & $0.16-0.84$ & $<0.001$ & 0.39 & $0.25-0.61$ & $<0.001$ & 1.44 & $1.08-1.93$ & $<0.001$ & 0.27 & $0.21-0.34$ & $<0.001$ \\
\hline 0.32 & $0.11-0.98$ & $<0.001$ & 0.39 & $0.18-0.82$ & $<0.001$ & 0.66 & $0.47-0.91$ & $<0.001$ & 0.30 & $0.22-0.43$ & $<0.001$ \\
\hline- & - & - & - & - & - & 0.47 & $0.30-0.73$ & $<0.001$ & 0.70 & $0.54-0.89$ & 0.004 \\
\hline - & - & - & - & - & - & - & - & - & 0.80 & $0.64-1.00$ & 0.054 \\
\hline . & - & - & - & - & - & - & - & - & 0.18 & $0.11-0.28$ & $<0.001$ \\
\hline
\end{tabular}


Table 4 Multivariable logistic regression of socio-demographics and pregnancy-related variables associated with caesarean deliveries (Continued)

\begin{tabular}{|c|c|c|c|c|c|c|c|c|c|c|c|c|}
\hline & \multicolumn{3}{|c|}{$\begin{array}{l}\text { PDHS 1990-91 } \\
(n=4029)\end{array}$} & \multicolumn{3}{|c|}{$\begin{array}{l}\text { PDHS 2006-07 } \\
(n=5721)\end{array}$} & \multicolumn{3}{|c|}{$\begin{array}{l}\text { PDHS 2012-13 } \\
(n=7461)\end{array}$} & \multicolumn{3}{|c|}{$\begin{array}{l}\text { PDHS 2017-18 } \\
(n=8287)\end{array}$} \\
\hline & AOR & $95 \% \mathrm{Cl}$ & $p$-value & AOR & $95 \% \mathrm{Cl}$ & $p$-value & AOR & $95 \% \mathrm{Cl}$ & $p$-value & $\overline{A O R}$ & $95 \% \mathrm{Cl}$ & $p$-value \\
\hline \multicolumn{13}{|c|}{ Pregnancy-related variables } \\
\hline \multicolumn{13}{|c|}{ Pregnancy complication } \\
\hline No & - & - & - & 1 & & & 1 & & & - & - & - \\
\hline Yes & - & - & - & 1.80 & $1.34-2.42$ & $<0.001$ & 1.31 & $1.11-1.55$ & 0.001 & - & - & - \\
\hline \multicolumn{13}{|c|}{ Number of antenatal care visits } \\
\hline None & 1 & & & 1 & & & 1 & & & 1 & & \\
\hline $1-3$ & 6.95 & $1.82-26.54$ & $<0.001$ & 1.30 & $0.82-2.06$ & 0.260 & 2.51 & $1.49-4.52$ & $<0.001$ & 1.49 & $0.93-2.37$ & 0.097 \\
\hline 4 and above & 9.64 & $2.61-35.61$ & $<0.001$ & 2.26 & $1.64-3.11$ & $<0.001$ & 4.24 & $4.67-6.42$ & $<0.001$ & 2.21 & $1.39-3.52$ & $<0.001$ \\
\hline \multicolumn{13}{|c|}{ Place of delivery } \\
\hline Public & - & - & - & - & - & - & 1 & & & 1 & & \\
\hline Private & - & - & - & - & - & - & 1.05 & $0.88-1.25$ & 0.627 & 1.45 & $1.26-1.68$ & $<0.001$ \\
\hline \multicolumn{13}{|c|}{ Size of the baby at birth } \\
\hline Below average & - & - & - & 1 & & & - & - & - & 1 & & \\
\hline Normal & - & - & - & 0.84 & $0.61-1.14$ & 0.259 & - & - & - & 1.08 & $0.80-1.45$ & 0.794 \\
\hline \multicolumn{13}{|c|}{ Number of children } \\
\hline $1-2$ & 1.22 & $0.30-4.93$ & 0.785 & 1.00 & $0.72-1.62$ & 0.930 & 0.70 & $0.44-1.13$ & 0.148 & 0.08 & $1.44-1.67$ & $<0.001$ \\
\hline $3-4$ & 0.74 & $0.30-1.84$ & 0.518 & 0.98 & $0.65-1.47$ & 0.924 & 1.09 & $0.86-1.80$ & 0.486 & 1.00 & $0.83-1.21$ & 0.971 \\
\hline 5 and above & 1 & & & 1 & & & 1 & & & 1 & & \\
\hline \multicolumn{13}{|c|}{ Pregnancy ever terminated } \\
\hline No & - & - & - & - & - & - & - & - & - & 1 & & \\
\hline Yes & - & - & - & - & - & - & - & - & - & 0.79 & $0.57-1.11$ & 0.550 \\
\hline
\end{tabular}

Multivariate logistic regression analysis was carried out to obtain AOR after entering all the independent variables simultaneously that were significant at level 0.05 in binary analysis

health care centres and hospitals in Pakistan over time. Arguably, the misuse of the surgical incision in private hospitals may involve varied factors. The high expenditure of a caesarean delivery, for example, can be considered as a significant factor that has resulted in increased rates of caesarean deliveries in private hospitals. Considering the situation in private hospitals, the doctors may prefer caesarean delivery over vaginal delivery for financial benefits and time convenience [33]. Additionally, the higher rates of caesarean deliveries in private hospitals tend not only to increase the cost of health care but they increase the health risks of women and newly born babies. However, the PDHSs (1990-2018) for both private and public hospitals lack the relevant information regarding the medical reasons for performing caesarean deliveries.

The literature shows that the low weight of baby at birth or a small size is not strongly associated with the caesarean delivery, as the mothers who were told about the low birth weight or the small size of the newborn at the time of birth had fewer chances to undergo caesarean delivery [33]. Similarly, results of the present study show that the size of the baby is not interlinked with the caesarean delivery, as mothers whose babies had below average size did not have a higher tendency to have a caesarean delivery.

\section{Limitations}

The data from the PDHSs have some limitations that tend to affect the findings of the study. First of all, the cross-sectional design does not allow for causal interpretations. While taking into consideration pregnancyrelated variables, the information related to pregnancy termination was not available in 2006-07 and 2012-13. Similarly, PDHS 2017-18 lacks the relevant information about pregnancy complications and, thus, affected the trend analysis of the respective variable in the present study. In addition, the information about birth weight is uncertain. Consequently, we used a combined variable on size and weight at birth to borrow strength. The data in all four PDHSs waves (1990-2018) do not offer relevant information on the nature of pregnancy complications experienced by a mother. Keeping in view the limited availability of data required, the present study is 
unable to highlight any particular pregnancy complication that led to a caesarean section delivery. The PDHS 1990-2018 data lacked the information to differentiate between medical and non-medical reasons for carrying out caesarean surgery, thus, the study could not discuss the misuse of surgical incision for child delivery as a contributing factor for the increase in the caesarean deliveries. Additionally, the dataset of PDHS 2017-18 does not include the information related to pregnancy complications.

\section{Conclusions}

The findings of the present study reveal a progressive increasing trend of caesarean deliveries in Pakistan over time (from $3.2 \%$ in 1990 to $19.6 \%$ in 2018). The data revealed a strong relationship between independent variables, including the age of a mother at birth, mothers living in an urban area, residing in Punjab province, having a higher socio-economic status and using more antenatal care, and delivering in private hospitals and the occurrence of caesarean surgery as a delivery mode. The findings of the study further recommend that the health system in Pakistan should provide clear medical guidelines to doctors for carrying out caesarean section deliveries. Strict adherence to those medical guidelines will help in reducing the rate of caesarean sections in both public and private hospitals in Pakistan. Moreover, awareness programmes as a part of antenatal care can create awareness among women related to pregnancy complications and childbirth processes that tend to minimize the use of not medically caesarean deliveries which are not medically indicated.

\section{Abbreviations}

AOR: Adjusted odds ratio; Cl: Confidence interval; DHS: Demographic and Health Survey; OR: Odds ratio; PDHS: Pakistan Demographic and Health Survey; WHO: World Health Organization

\section{Acknowledgements}

We acknowledge support from the German Research Foundation (DFG) and the Open Access Publication Fund of Charité - Universitätsmedizin Berlin.

\section{Authors' contributions}

$A A, A l$ and NS drafted the initial manuscript and were responsible for data analysis. RZ, MZ and FF supervised the data analysis. RZ, AU, MZ and FF revised the manuscript critically for important intellectual content. All authors read and approved the final version of the manuscript.

\section{Funding}

This research received no supporting funds from any funding agency in the public, commercial, or not-for-profit sector. Open Access funding enabled and organized by Projekt DEAL.

Availability of data and materials

Data are available from the DHS programme at https://dhsprogram.com/.

\section{Ethics approval and consent to participate}

The research used publicly available secondary data from two waves of PDHS. Hence, ethical approval was not required.
Consent for publication

Not applicable.

\section{Competing interests}

The authors declare that there is no competing interest.

\section{Author details}

'Institute of Social and Cultural Studies, University of the Punjab, Lahore, Pakistan. ${ }^{2}$ Department of Public Health, Institute of Social and Cultural Studies, University of the Punjab, Lahore, Pakistan. ${ }^{3}$ University of Okara, Okara, Pakistan. ${ }^{4}$ Institute of Public Health, Charité - Universitätsmedizin Berlin, Berlin, Germany. ${ }^{5}$ Institute of Gerontological Health Services and Nursing Research, Ravensburg-Weingarten University of Applied Sciences, Weingarten, Germany.

Received: 27 March 2020 Accepted: 25 November 2020

Published online: 02 December 2020

\section{References}

1. Norheim OF, Jha P, Admasu K, Godal T, Hum RJ, Kruk ME, et al. Avoiding $40 \%$ of the premature deaths in each country, 2010-30: review of national mortality trends to help quantify the UN sustainable development goal for health. Lancet. 2015;385(9964):239-52.

2. Bhutta ZA, Cabral S, Chan CW, Keenan WJ. Reducing maternal, newborn, and infant mortality globally: an integrated action agenda. Int J Gynecol Obstet. 2012;119(Suppl. 1):S13-7.

3. Liu S, Rusen ID, Joseph KS, Liston R, Kramer MS, Wen SW, et al. Recent trends in caesarean delivery rates and indications for caesarean delivery in Canada. J Obstet Gynaecol Can. 2004;26(8):735-42.

4. Amjad A, Amjad U, Zakar R, Usman A, Zakar MZ, Fischer F. Factors associated with caesarean deliveries among child-bearing women in Pakistan: secondary analysis of data from the demographic and health survey, 2012-13. BMC Pregnancy Childbirth. 2018;18:113.

5. Niino $Y$. The increasing caesarean rate globally and what we can do about it. Biosci Trends. 2018;5(4):139-50.

6. Boatin AA, Schlotheuber A, Betran AP, Moller AB, Barros AJ, Boerma T, et al. Within country inequalities in caesarean section rates: observational study of 72 low- and middle-income countries. BMJ. 2018;360:k55.

7. World Health Organization. WHO statement on caesarean section rates. Geneva: World Health Organization; 2015.

8. Molina G, Weiser TG, Lipsitz SR, Esquivel MM, Uribe-Leitz T, Azad T, et al. Relationship between caesarean delivery rate and maternal and neonatal mortality. JAMA. 2015;314(21):2263-70.

9. Althabe F, Sosa C, Belizán JM, Gibbons L, Jacquerioz F, Bergel E. Caesarean section rates and maternal and neonatal mortality in low-, medium-, and high-income countries: an ecological study. Birth. 2006;33(4):270-7.

10. Solheim KN, Esakoff TF, Little SE, Cheng YW, Sparks TN, Caughey AB. The effect of caesarean delivery rates on the future incidence of placenta previa, placenta accreta, and maternal mortality. J Matern Fetal Neonatal Med. 2011;24(11):1341-6.

11. Black M, Bhattacharya S, Philip S, Norman JE, McLernon DJ. Planned caesarean delivery at term and adverse outcomes in childhood health. JAMA. 2015;314(21):2271-9.

12. Penna L, Arulkumaran S. Caesarean section for non-medical reasons. Int J Gynecol Obstet. 2003;82(3):399-409.

13. Hildingsson I, Rådestad I, Rubertsson C, Waldenström U. Few women wish to be delivered by caesarean section. BJOG Int J Obstet Gynaecol. 2002; 109(6):618-23.

14. Mylonas I, Friese K. Indications for and risks of elective caesarean section. Dtsch Arztebl Int. 2015;112(29-30):489.

15. Mumtaz S, Bahk J, Khang YH. Rising trends and inequalities in cesarean section rates in Pakistan: evidence from Pakistan demographic and health surveys, 1990-2013. PLoS One. 2017;12(10):e0186563.

16. Hafeez M, Yasin A, Badar N, Pasha Ml, Akram N, Gulzar B. Prevalence and indications of caesarean section in a teaching hospital. JIMSA. 2014;27:15-6.

17. Iftikhar T, Rizvi U, Ejaz L. Evaluation of causes of increasing caesarean section rate in tertiary care hospital. J Sheikh Zayed Med Coll. 2010;1:1.

18. Martinez PA. C-section boom: all about the \$?. 2013. http://www.parents. com/blogs/everything-pregnancy/2013/09/04/must-read/caesarean-sectionbirth-monetary-incentive/. Accessed 10 Aug 2015. 
19. Bayrambour H, Heaman M. Advanced maternal age and the risk of caesarean birth: a systematic review. Birth. 2010;37(3):219-26.

20. Carolan M, Davey M-A, Biro MA, Kealy M. Older maternal age and intervention in labor: a population-based study comparing older and younger first-time mothers in Victoria, Australia. Birth. 2011;38(1):24-9.

21. Jahromi BN, Husseini Z. Pregnancy outcome at maternal age 40 and older. Taiwanese J Obstet Gynecol. 2008;47(3):318-21.

22. Hanif HM. Association between maternal age and pregnancy outcome: implications for the Pakistani society. J Pak Med Assoc. 2011;61:313-9.

23. Lin HC, Sheen TC, Tang CH, Kao S. Association between maternal age and the likelihood of a caesarean section: a population-based multivariate logistic regression analysis. Acta Obstet Gynecol Scand. 2004;83:1178-83.

24. Padmadas SS, Suresh KS, Nair SB, Anitha Kumari KR. Caesarean section delivery in Kerala, India: Evidence from National Family Health Survey. Soc Sci Medl Sci. 2000:519(4):511-2.

25. Weiss JL, Malone FD, Emig D, Ball RH, Nyberg DA, Comstock CH, et al. Obesity, obstetric complications and caesarean delivery rate - a populationbased screening study. Am J Obstet Gynecol. 2004;190(4):1091-7.

26. Dražančić A. Antenatal care in developing countries. What should be done? J Perinat Med. 2001;29(3):188-98.

27. Walker DS, McCully L, Vest V. Evidence-based prenatal care visits: when less is more. J Midwifery Women's Health. 2001;46(3):146-51.

28. Majrooh MA, Hasnain S, Akram J, Siddiqui A, Memon ZA. Coverage and quality of antenatal care provided at primary health care facilities in the 'Punjab' province of 'Pakistan'. PLoS One. 2014;9(11):e113390.

29. Islam MT, Yoshimura Y. Rate of caesarean delivery at hospitals providing emergency obstetric care in Bangladesh. Int J Gynecol Obstet. 2015; 128(1):40-3.

30. Kambo I, Bedi N, Dhillon BS, Saxena NC. A critical appraisal of caesarean section rates at teaching hospitals in India. Int J Gynecol Obstet. 2002;79(2):151-8.

31. Ronsmans C, Holtz S, Stanton C. Socioeconomic differentials in caesarean rates in developing countries: a retrospective analysis. Lancet. 2006; 368(9546):1516-23.

32. Blencowe H, Cousens S, Jassir FB, Say L, Chou D, Mathers C, et al. National, regional, and worldwide estimates of stillbirth rates in 2015, with trends from 2000: a systematic analysis. Lancet Glob Health. 2016;4(2):e98-108.

33. Singh P, Hashmi G, Swain PK. High prevalence of caesarean section births in private sector health facilities-analysis of district level household survey-4 (DLHS-4) of India. BMC Public Health. 2018;18:613.

34. Malloy MH, Rhoads GG, Schramm W, Land G. Increasing caesarean section rates in very low - birth weight infants: effect on outcome. JAMA. 2009; 262(11):1475-8.

\section{Publisher's Note}

Springer Nature remains neutral with regard to jurisdictional claims in published maps and institutional affiliations.

Ready to submit your research? Choose BMC and benefit from:

- fast, convenient online submission

- thorough peer review by experienced researchers in your field

- rapid publication on acceptance

- support for research data, including large and complex data types

- gold Open Access which fosters wider collaboration and increased citations

- maximum visibility for your research: over $100 \mathrm{M}$ website views per year

At $\mathrm{BMC}$, research is always in progress.

Learn more biomedcentral.com/submissions 